\title{
Localization of DNA methyltransferase-1 during oocyte differentiation, in vitro maturation and early embryonic development in cow
}

\author{
V. Lodde, S.C. Modina, F. Franciosi, E. Zuccari, I. Tessaro, A.M. Luciano ${ }^{1}$ \\ Division of Veterinary Anatomy and Histology, Department of Animal Sciences, Faculty of \\ Veterinary Medicine, University of Milan, Milan, Italy
}

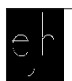

(C)2009 European Journal of Histochemistry

DNA methyltransferase-1 (Dnmt1) is involved in the maintenance of DNA methylation patterns and is crucial for normal mammalian development. The aim of the present study was to assess the localization of Dnmt1 in cow, during the latest phases of oocyte differentiation and during the early stages of segmentation. Dnmt1 expression and localization were assessed in oocytes according to the chromatin configuration, which in turn provides an important epigenetic mechanism for the control of global gene expression and represents a morphological marker of oocyte differentiation. We found that the initial chromatin condensation was accompanied by a slight increase in the level of global DNA methylation, as assessed by 5-methyl-cytosine immunostaining followed by laser scanning confocal microscopy analysis (LSCM). RT-PCR confirmed the presence of Dnmt1 transcripts throughout this phase of oocyte differentiation. Analogously, Dnmt1 immunodetection and LSCM indicated that the protein was always present and localized in the cytoplasm, regardless the chromatin configuration and the level of global DNA methylation. Moreover, our data indicate that while Dnmt1 is retained in the cytoplasm in metaphase II stage oocytes and zygotes, it enters the nuclei of 8-16 cell stage embryos. As suggested in mouse, the functional meaning of the presence of Dnmt1 in the bovine embryo nuclei could be the maintainement of the methylation pattern of imprinted genes. In conclusion, the present work provides useful elements for the study of Dnmt1 function during the late stage of oocyte differentiation, maturation and early embryonic development in mammals.

Key words: Dnmt1, Methylation, chromatin, oogenesis, meiosis, embryogenesis.

Correspondence: Alberto M. Luciano,

Sezione di Anatomia ed Istologia Veterinaria, Dipartimento di Scienze Animali, Facoltà di Medicina Veterinaria, Università degli Studi di Milano, Via Celoria, 10 - 20133 Milano - Italy Tel.: +39.0250317969.

Fax: +39.02 50317980 .

E-mail: alberto.luciano@unimi.it

Paper accepted on September 10, 2009

European Journal of Histochemistry

2009; vol. 53 issue 4 (October-December): 199-208
I $\mathrm{n}$ mammals, the establishment and maintenance of DNA methylation patterns play an important role in the regulation of gene expression and genomic imprinting, and are crucial for normal embryonic development (reviewed in: Bird, 2002; Li, 2002; Reik et al., 2001). Genomic methylation patterns undergo drastic changes during gametogenesis and early embryonic development. This process has been extensively studied in mice using different experimental approaches. In the germ line, methylation patterns are erased early in development and gamete-specific ones are established at imprinted loci during gametogenesis (reviewed in: Li, 2002; Reik et al., 2001). In the oocyte, an overall increase in global DNA methylation has been reported during the oocyte growth phase, reaching the highest level in the fully grown oocyte at the germinal vesicle (GV) stage (Kageyama et al., 2007; Spinaci et al., 2004). After fertilization, the zygote undergoes extensive demethylation. Genomic DNA of paternal origin is actively demethylated within several hours after fertilization, whereas the oocyte-derived maternal genome is thought to be passively demethylated (Mayer et al., 2000; Oswald et al., 2000; Rougier et al., 1998; Santos et al., 2002; Cardoso and Leonhardt, 1999; Carlson et al., 1992; Howell et al., 2001; Mertineit et al., 1998). During this phase the monoallelic methylation marks of the imprinted genes escape demethylation and are faithfully maintained (reviewed in: Li, 2002; Reik et al., 2001). De novo and maintenance DNA methylation throughout the genome is restored around the time of implantation to establish tissue-specific epigenetic state (Kafri et al., 1993; Monk et al., 1987; Santos et al., 2002).

DNA methyltransferases (Dnmts) are responsible for the establishment and the maintenance of methylation patterns. In contrast to Dnmt3a and 3b, which catalyze de novo methylation of unmethylated DNA, Dnmtl is a maintenance enzyme that 
methylates hemi-methylated $\mathrm{CPG}$ dinucleotides in the nascent strand of DNA after replication (reviewed in: Bestor, 2000; Li, 2002). Two different isoforms of Dnmtl have been found in mouse, named Dnmtlo and Dnmtls, which derive by alternative splicing of the Dnmtl gene. While Dnmtls protein is ubiquitously expressed, Dnmtlo is predominantly expressed in the mouse oocyte and preimplantation embryo (Bestor, 2000; Mertineit et al., 1998). The oocyte specific isoform of Dnmtl has been found in monkey (Vassena et al., 2005) and pig (Jeong et al., 2009) and a novel Dnmtl isoform was found to be expressed in sheep oocyte, embryo and early fetal lineage, but not in the adult tissue (Taylor et al., 2009). On the contrary, two independent studies indicate that the expression of an oocyte specific isoform of Dnmtl is unlikely to occur in cattle (Golding and Westhusin, 2003; Russell and Betts, 2008). In mouse, Dnmtlo is thought to be implicated in the maintenance of DNA methylation of imprinted genes at the 8-cells stage of development, when it translocates into the nuclei for one cell cycle (Carlson et al., 1992; Howell et al., 2001; Ratnam et al., 2002). However it is unclear how the methylation imprints are maintained through extensive demethylation in cleavage-stage preimplantation embryos other than the 8 cells stage. Interestingly, new evidences have demonstrated that Dnmtls is present in association with chromatin in metaphase II stage (MII) oocyte and preimplantation embryo (Cirio et al., 2008; Kurihara et al., 2008) and that Dnmtl alone is sufficient to maintain the methylation marks of the imprinted genes (Hirasawa et al., 2008).

To date the possible involvement of Dnmtl in the process of DNA methylation during bovine development is poorly understood. Moreover, since the methylation reprogramming events that presumably involve Dnmtl during bovine development are to some extent different from those of the mouse, comparative studies of Dnmtl expression are of mechanistic interest. To address these issues, we investigated the localization of Dnmtl during the latest phase of the oocyte growth, differentiation and in vitro maturation as well as during the early embryonic development until the 8-16 cells stage. To investigate the possible involvement of Dnmtl in the DNA methylation process of the oocyte genome, we analyzed the Dnmtl expression and localization according to the chromatin configuration of bovine oocyte as previous studies indicated that different pattern of chromatin configuration could represent a morphological marker of oocyte differentiation (Lodde et al., 2007; Lodde et al., 2008). Moreover, to correlate the Dnmtl localization with the DNA methylation patterns during oogenesis we also characterized the DNA methylation by immunohistochemical studies using antibodies against 5methyl-cytosine.

\section{Materials and Methods}

\section{Chemicals and Reagents}

All chemicals and reagents were purchased from Sigma Chemical Company (St. Louis, USA), unless otherwise stated.

\section{Oocytes collection}

Bovine ovaries were recovered at the abattoir (INALCA spa, Ospedaletto Lodigiano, LO, Ric. CEE $2270 \mathrm{M}$, Italy) from pubertal females subjected to routine veterinary inspection and in accordance to the specific health requirements stated in Council Directive 89/556/ECC and subsequent modifications. Ovaries were transported to the laboratory, within 2 hours, in sterile saline $(9 \mathrm{~g}$ $\mathrm{NaCl} / \mathrm{L}$ ) maintained at $26^{\circ} \mathrm{C}$. All subsequent procedures, unless differently specified, were performed at $35-38^{\circ} \mathrm{C}$. Oocytes at different stage of differentiation were collected from early $(0.5-<2 \mathrm{~mm})$ and middle $(2-6 \mathrm{~mm})$ antral follicles as previously described (Lodde et al., 2007; Lodde et al., 2008). Cumulus-oocyte complexes (COCs) were retrieved from middle antral follicles with a 16-gauge needle mounted on an aspiration pump (COOK-IVF, Brisbane QLD, Australia). After aspiration, small pieces of ovarian cortex were removed and examined under a dissecting microscope. COCs were isolated from early antral follicles by rupturing the follicle wall with a scalpel. COCs were washed in M199 supplemented with HEPES 20 mM, 1790 units/L Heparin and $0.4 \%$ of bovine serum albumin (BSA) and examined under a stereomicroscope. Only COCs medium-brown in color, with five or more complete layers of cumulus cells and a finely granulated homogenous ooplasm were used.

\section{In vitro maturation, fertilization and embryo culture}

Mature bovine oocytes, zygotes and preimplantation stage embryos were obtained using standard procedures utilized in our laboratory for in vitro 
embryo production (Luciano et al., 2005). COCs harvested from middle antral follicles were matured in four-well dishes (NUNC, VWR International, Milan, Italy), for $24 \mathrm{~h}$ at $38.5^{\circ} \mathrm{C}$ under $5 \% \mathrm{CO}_{2}$ in humidified air in TCM-199, supplemented with 0.68 $\mathrm{mM}$ L-glutamine, $25 \mathrm{mM} \mathrm{NaHCO} 3,0.4 \%$ of bovine serum albumin fatty acid free, $0.2 \mathrm{mM}$ of sodium pyruvate and $0.1 \mathrm{IU} / \mathrm{mL}$ of recombinant human FSH (rhFSH, Gonal-F, Serono, Rome, Italy). After in vitro maturation, oocytes were fertilized as previously described (Luciano et al., 2005). Briefly, the contents of a straw of cryopreserved bull spermatozoa (CIZ, S. Miniato Pisa, Italy) was thawed and cells separated on a 45-90\% Percoll gradient. Sperms were counted and diluted to a final concentration of $0.5 \times 10^{6}$ spermatozoa $/ \mathrm{mL}$ in fertilization medium that was a modified Tyrode's solution (TALP) supplemented with $0.6 \%(\mathrm{w} / \mathrm{v})$ BSA fatty acid free, $10 \mu \mathrm{g} / \mathrm{mL}$ heparin, $20 \mu \mathrm{M}$ penicillamine, 1 $\mu \mathrm{M}$ epinephrine, and $100 \mu \mathrm{M}$ hypotaurine. COCs and sperms were incubated for 18 hours at $38.5^{\circ} \mathrm{C}$ under $5 \% \mathrm{CO}_{2}$ in humidified air.

After in vitro fertilization, presumptive zygotes were washed and cumulus cells were removed by vortexing for 2 min in $500 \mu \mathrm{L}$ of a synthetic oviduct fluid (SOF: Tervit et al., 1972) supplemented with $0.3 \%(\mathrm{w} / \mathrm{v})$ BSA fraction $\mathrm{V}$, fatty acid free, MEM essential and non-essential aminoacids, $0.72 \mathrm{mM}$ of sodium pyruvate, and buffered with $10 \mathrm{mM}$ of HEPES and $5 \mathrm{mM}$ of $\mathrm{NaHCO}_{3}$. Presumptive zygotes were rinsed and transferred in embryo culture medium, which was SOF buffered with $25 \mathrm{mM}$ of $\mathrm{NaHCO}_{3}$, supplemented with MEM essential and non-essential aminoacids, $0.72 \mathrm{mM}$ of sodium pyruvate, $2.74 \mathrm{mM}$ of myo-inositol, $0.34 \mathrm{mM}$ of sodium citrate and with $5 \%$ of calf serum (Gibco, Invitrogen, San Giuliano Milanese, Milan, Italy). Incubation was performed at $38.5^{\circ} \mathrm{C}$ under $5 \%$ $\mathrm{CO}_{2}, 5 \% \mathrm{O}_{2}$ and $90 \% \mathrm{~N}_{2}$ in humidified air. Zygotes and 8-16 cells stage embryos were collected after 18 and 90 hours post insemination, respectively.

\section{Immunofluorescence staining}

Indirect immunofuorescence was carried out to evaluate the Dnmtl cellular localization in oocytes collected from early and middle antral follicles, zygotes and 8-16 cells stage embryos. Oocytes were freed of cumulus cells by vortexing 2 min and fixed as previously described (Modina et al., 2004). Before fixation the zona pellucida of all the samples was digested with $0.5 \%$ of pronase according to (Modina et al., 2004). Samples were fixed in $4 \%$ paraformaldehyde in phosphate buffer saline (PBS) for $1 \mathrm{~h}$ at $4{ }^{\circ} \mathrm{C}$, washed in $0.05 \%$ Tween 20 in PBS and permeabilized with $0.2 \%$ Triton X100, $0.05 \%$ Tween 20 in PBS for 30 min at room temperature (RT). Non specific binding was blocked by incubating the samples in $20 \%$ normal rabbit serum, $1 \%$ BSA in PBS for $1 \mathrm{~h}$ at RT. The samples were incubated overnight at $4^{\circ} \mathrm{C}$ with a polyclonal goat antibody anti-Dnmtl (Santa Cruz Biotechnology, Santa Cruz, CA, USA) diluted 1:25 in PBS containing $1 \%$ BSA and $0.05 \%$ Tween 20 . Specificity and cross-reactivity with bovine was confirmed by the manufacturer. Samples were extensively washed in $0.05 \%$ Tween 20 in PBS and incubated for $1 \mathrm{~h}$ at RT with a rabbit anti goat secondary antibody conjugated with Alexa Fluor 488 (Invitrogen), diluted 1:500 in PBS containing 1\% BSA and $0.05 \%$ Tween 20 . For the immunostaining of 8-16 cells stage embryos, PBS with 100 $\mathrm{mg} / \mathrm{ml}$ of Calcium chloride and $100 \mathrm{mg} / \mathrm{ml}$ of Magnesium chloride, was used instead of PBS to avoid blastomeres separation after removal of the zona pellucida.

DNA methylation was detected on oocytes collected from early and middle antral follicles with a mouse anti-5-methylcytosine (Eurogentec SA, Seraing Belgium, 1:500), according to the above protocol except that oocytes were treated in $2 \mathrm{M}$ $\mathrm{HCl}$ for 30 min at RT to obtain DNA denaturation and then neutralized in $100 \mathrm{mM}$ Tris $\mathrm{HCl}$ buffer ( $\mathrm{pH}$ 8.5) for 10 min before primary antibody incubation. Normal donkey serum was used to block non specific boundary of the secondary antibody that was a donkey anti mouse conjugated with Alexa Fluor 488 (Invitrogen, 1:500).

All the samples were rinsed twice in $0.05 \%$ Tween 20 in PBS and mounted in an antifade medium (Vecta Shield; Vector Laboratories, Inc., Burlingame, CA) supplemented with DAPI dilactate $(1 \mu \mathrm{g} / \mathrm{mL})$. In each experiment, negative controls were performed by omitting the primary antibody. Samples were analyzed on a Nikon Clsi confocal laser scanning microscope (Nikon Corp. Tokyo, Japan). When the DNA methylation patterns were analyzed according to the GV chromatin configuration, digital optical sections were obtained by scanning the sample on z-axis at $0.5 \mu \mathrm{m}$ of thickness throughout the plane of focus containing the GV equatorial plane. The z-series were then projected to obtain a three dimensional image. Instrument 
settings were kept constant for each sample; analysis was conducted on digitalized images.

\section{RNA isolation and RT-PCR}

Gene expression of Dnmtl was examined by standard RT-PCR. Oocytes collected from early and middle antral follicles were freed of cumulus cells and divided according to their chromatin configuration as previously described (Lodde et al., 2007; Lodde et al., 2008). Briefly, denuded oocytes (DOs) were obtained by mechanically removing of cumulus cells by the use of vortex ( $2 \mathrm{~min}, 35 \mathrm{Htz}$ ) in M199 supplemented with HEPES $20 \mathrm{mM}$ and with $5 \%$ of calf serum (HM199). DOs were twice washed in HMI99, stained with $1 \mu \mathrm{g} / \mathrm{mL}$ Hoechst 33342 in HM199 for 5 min in the dark, and then individually transferred into a $5 \mu \mathrm{L}$ drop of the same medium, overlaid with mineral oil. Chromatin organization was evaluated under an inverted fluorescence microscope (Olympus IX50, Tokyo, Japan, magnification 40X), equipped with a CCD camera (3CCD Color Video Camera JVC, Model KYF55B). Oocytes were exposed to fluorescence irradiation for no more than 3 seconds, classified and grouped according to the degree of chromatin condensation within the nuclear envelope. Total RNA was extracted from groups of oocytes (25 for each stage) using the RNeasy Plus Mini Kit (Quiagen, Milan, Italy) according to the manufacturer instruction. Total RNA was then retro-transcribed with random examers using the SuperScript FirstStrand Synthesis System (Invitrogen). Groups of denuded oocytes from middle antral follicles were processed as control. A total amount of cDNA equivalent to 5 oocytes was used in each amplification reaction. Amplification was performed with specific primers for Dnmtls according to Golding and Westhsin (2003) (Gene Bank AY244709; Forward primer: 5'-gatgcctgcccgaaccg-3'; Reverse primer: 5'cccgtgggaaatgagatgtgat $-3^{\prime} ;$; amplification product: 521 bp). As internal control, $\beta$ actin expression was tested in each GV category (Gene Bank N M 173979; Forward primer: 5'-tgaaccctaaggccaaccgtg-3'; Reverse primer: 5'-tgtagccacgctcggtcagga -3', amplification product: $268 \mathrm{bp}$ ). Beta actin primers were designed to span introns and thus to evaluate the presence of contaminating DNA in RNA samples. PCR amplification products were analyzed by electrophoresis on a $2 \%$ agarose gel. RT-PCR experiments were repeated on three RNA samples from independently collected and extracted oocytes for each experimental group.

\section{Results}

\section{DNA methylation pattern and localization of bovine DNA methyltransferase-1 during oocyte differentiation}

Chromatin configuration patterns obtained in GV stage bovine oocytes after confocal analysis confirmed previous observations made by epifluorescence microscopy (Lodde et al., 2007; Lodde et al., 2008). As shown in Figure $1(E, F, G, H)$ and $3(E, F, G, H)$, four discrete stages characterized by a progressive increase of chromatin condensation were identified.

The GV0 stage was characterized by a diffuse filamentous pattern of chromatin in the whole nuclear area. The GVI stage was similar to the GV0 configuration except that few chromatin foci of condensation could be detected in the nucleus. In the GV2 stage, chromatin was further condensed into distinct clumps or strands, while in the GV3 stage the chromatin was condensed into a single clump. As previously shown, almost all oocytes collected from early antral follicles were classified as GV0. This class was absent in middle antral follicles, where the classes $G V 1, G V 2$ and GV3 occurred at similar frequency.

The DNA methylation analysis was conducted on a total of $93 \mathrm{GV}$ stage oocytes collected from early and middle antral follicles. Fluorescence intensity was arbitrarily classified as weak or high. As indicated in Figure 1, DNA methylation was already established in GVO stage oocytes from early antral follicles. However, a slight increase of DNA methylation levels was observed in the transition from GVO to GVI oocyte. On a total of 18 GV0 oocyte analyzed, only 7 showed intense fluorescence labeling, while 9 showed a weak signal and 2 showed no labeling. On the contrary, high levels of DNA methylation were observed in all the oocytes bearing to $G V 1, G V 2$ and $G V 3$ stages (20,27 and 28 respectively) from middle antral follicles.

Analysis of gene expression by RT-PCR confirmed the presence of Dnmtl transcripts in all the observed GV stages (Figure 2). Immunofluorescence staining of Dnmtl showed that the protein was present throughout the cytoplasm (Figure 3 ) in all the 43 oocytes analyzed ( 9 GV0, $11 \mathrm{GV1}, 11 \mathrm{GV} 2,12 \mathrm{GV} 3$ ), while it was undetectable in the nuclear compartment. 

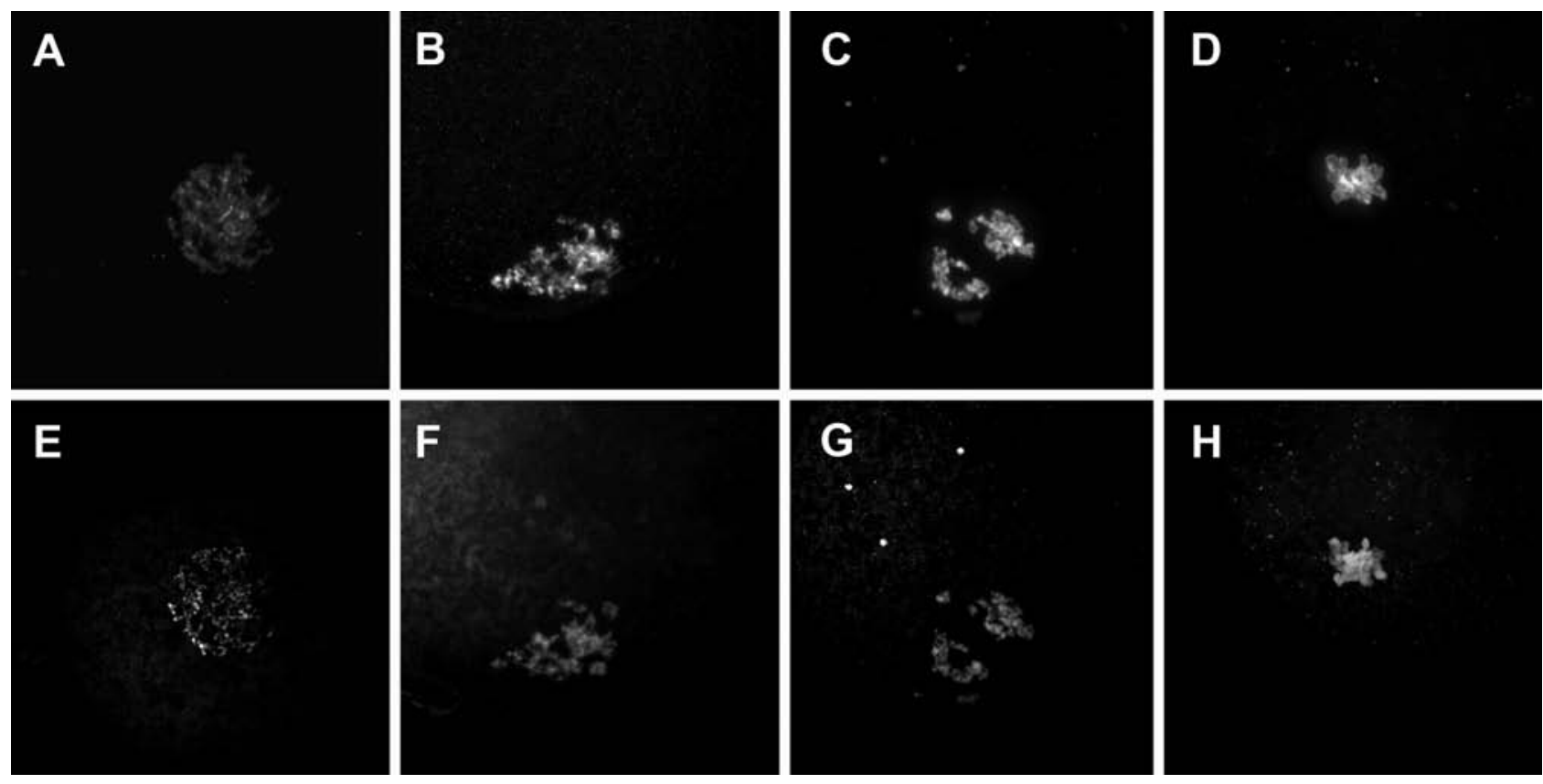

Figure 1. Global DNA methylation in GV stages bovine oocytes. Representative digital images of bovine oocytes, showing global DNA methylation patterns and chromatin configuration of GV0 (A, E), GV1 (B, F), GV2 (C, G) and GV3 (D, H) stage bovine oocytes. Chromatin counterstaining was performed with DAPI (E-H), while global DNA methylation was performed with a 5-methylcytosine antibody (A-D). All the images are the three-dimensional confocal reconstructions of each sample. In A is shown a GVO stage oocyte with a weak DNA methylation signal while B, C and D represent GV1, GV2 and GV3 oocytes with highly methylated DNA. Original magnification 60X.

\section{Localization of bovine DNA methyltransferase-1 in matured oocytes, zygotes and 8-16 cells stage embryos}

Immunofluorescence localization was conducted on 13 MII stage oocytes, 14 zygotes and 12 8-16 cells stage embryos. As shown in Figure 4 ( $A, B$ and C, D), Dnmtl was cytoplasmic in all the MII stage oocytes and zygotes analyzed and in all the blastomeres of 8-16 cells stage embryos (Figure 4, E$\mathrm{J})$. Interestingly, at this stage we identified three
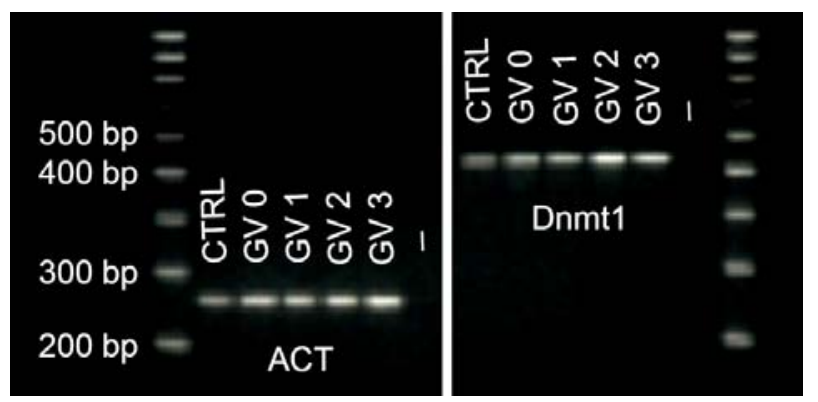

Figure 2. Dnmt1 gene expression analysis in bovine oocytes according to chromatin configuration. Representative RT-PCR reactions showing Dnmt1 and B-Actin (internal control) expression in each GV category. Note the presence of the Dnmt1 expected amplification product of $521 \mathrm{bp}$ in all the samples considered. patterns of Dnmtl localization with respect to the nuclear compartment. Dnmtl was found in the nuclei of several blastomeres (Figure 4, E and F), while was exclusively cytoplasmic in some others (Figure 4, G and H). Finally, Dnmtl was found more concentrated in the perinuclear region in certain blastomeres (Figure 4, I and J). The Dnmtl nuclear localization was not related to the embryonic cell number and occasionally, in the same embryo, blastomeres with different patterns were observed.

\section{Discussion}

The aim of our study was to assess the localization of Dnmtl during the latest phases of oocyte differentiation as well as during the early stage of embryonic development in order to evaluate its possible involvement in the process of DNA methylation during bovine development. Most of the knowledge on Dnmtl functions is based on studies in mice. However studies in other mammals, including cow (Beaujean et al., 2004; Dean et al., 2003; Dean et al., 2001; Lepikhov et al., 2008; Maalouf et al., 2008), revealed that methylation reprogram- 

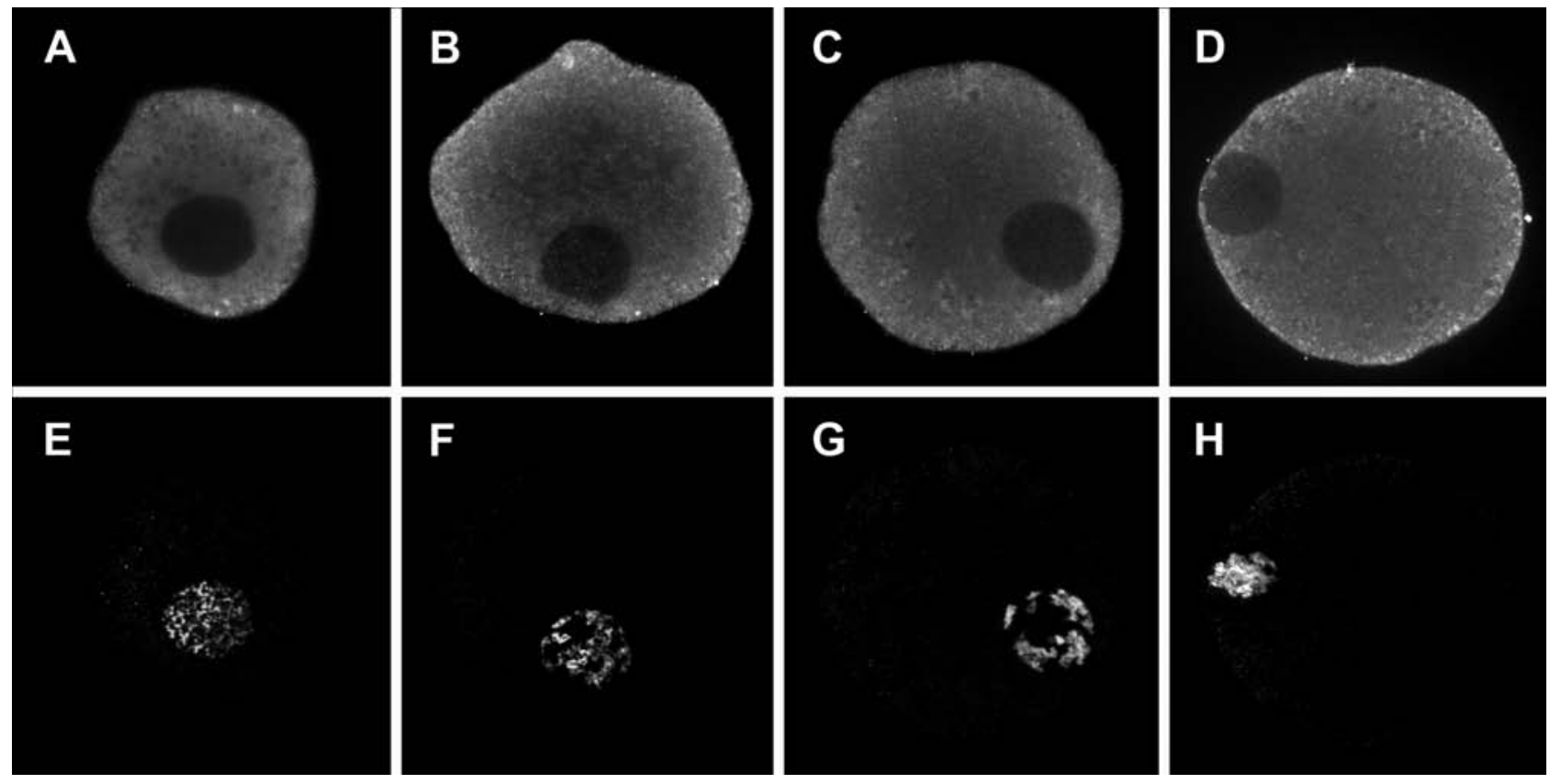

Figure 3. Dnmt1 localization in GV stages bovine oocytes. Representative digital images of bovine oocytes, showing Dnmt1 localization according to chromatin configuration of GV0 (A, E), GV1 (B, F), GV2 (C, G) and GV3 (D, H) stage bovine oocytes. Chromatin counterstaining was performed with DAPI (E-H), while Dnmt1 localization was analyzed by an anti Dnmt1 antibody (A-D). Images showing chromatin configuration are the three-dimensional confocal reconstructions of each sample, while images showing Dnmt1 localization are the digital optical section obtained by scanning the plane of focus containing the GV equatorial plane. Original magnification 60X.

ming events occurring in mouse early development do not necessarily reflect those of the other species as the extent and timing of the epigenetic events throughout preimplantation development can be different between mammals (Beaujean et al., 2004; Dean et al., 2003; Dean et al., 2001; Lepikhov et al., 2008; Oswald et al., 2000; Reik et al., 2003; Santos et al., 2002). Moreover, in the cow the oocyte specific isoform of Dnmtl (Dnmt10) was not found to be expressed in oocytes and embryos (Golding and Westhusin, 2003; Russell and Betts, 2008).

In the present work, we analyzed the localization of Dnmtl at two critical junctures during oogenesis, i.e. the periods of acquisition of maturation and embryonic developmental competences. Our previous studies indicated that the structural chromatin transitions in the oocyte nucleus are temporally related to the main morphological and functional events that characterize the final growth phase in bovine oocyte and thus representing a marker of oocyte differentiation. In particular, the transition from the GVO to the GVI stage has been related to the global transcription silencing and to the acquisition of meiotic competence, while the transition from the GVI stage to higher degrees of condensa- tion in GV2 and GV3 stage oocytes marks the acquisition of a full embryonic developmental capability (Lodde et al., 2007; Lodde et al., 2008). Although DNA methylation patterns in bovine oocytes and early embryos have been already documented in previous reports (Bourc'his et al., 2001; Dean et al., 2001; Kang et al., 2001; Maalouf et al., 2008), the present study analyzes for the first time this epigenetic mark according to the chromatin configuration changes. Our data indicate that DNA methylation is already established in GVO stage oocytes and slightly increases thereafter with chromatin condensation in GVI oocytes, which in turn seems to mark the achievement of a stable level of global DNA methylation as no further differences where observed between GVI, GV2 and GV3 stages oocytes. The increased DNA methylation from GVO to GVI stage oocytes correlates with the decrease of transcriptional activity that was observed during this transition (Lodde et al., 2008). In fact, a growing body of evidence indicates that the chromatin structure together with DNA methylation mutually reinforce the transcriptional repressive state of DNA (Bird, 2002; Fuks et al., 2003). Moreover, the low level of global DNA methylation in GVO oocytes is in accordance with 

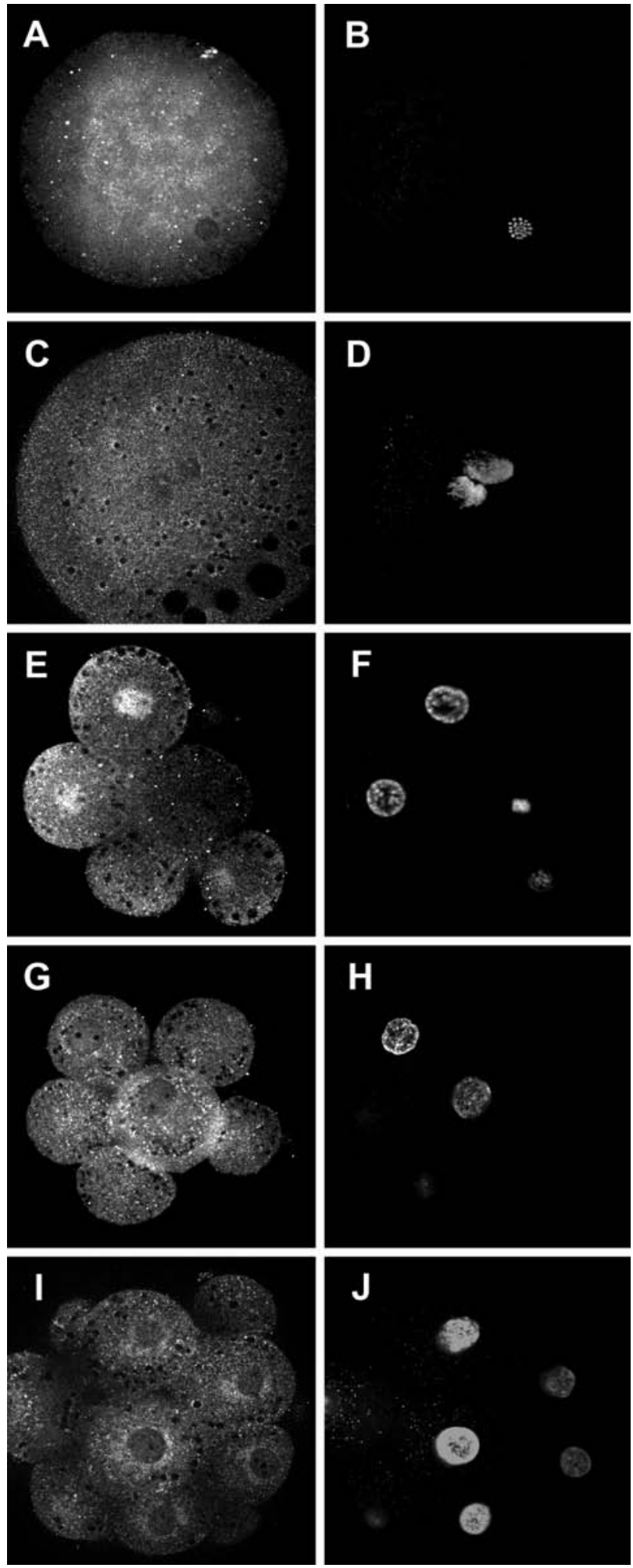

Figure 4. Dnmt1 localization in bovine MII stage oocytes, zygotes and early embryos: Representative confocal images showing Dnmt1 localization in MII stage oocyte (A, B), zygotes (C, D) and 8-16 cells stage embryos (E-J). Nuclear counterstaining was performed with DAPI (B, D, F, H and J), while Dnmt1 localization was analyzed by a specific antibody (A, C, E, G and I). All the panels represent confocal $Z$ sections. Original Magnification 60X. their limited competences as it is becoming evident that genome wide epigenetic modifications must be set in place during gametogenesis in order to allow a correct developmental program (Albertini et al., 2003; Bao et al., 2000; De La Fuente, 2006; Li, 2002). RT-PCR analysis confirmed the presence of the somatic form of Dnmtl transcripts in immature bovine oocytes as previously observed (Golding and Westhusin, 2003; Russell and Betts, 2008). Moreover this transcript was always detectable throughout the final phase of oocyte differentiation, independently on the chromatin configuration. Analogously, Dnmtl protein was always present and its localization did not vary during oocyte differentiation as it was found in the cytoplasm of all the oocytes analyzed. This could indicate that Dnmtl is not engaged in DNA methylation during the later phase of oocyte differentiation. This is in accordance with studies in mouse (Hirasawa et al., 2008; Mertineit et al., 1998), and sheep (Russo et al., 2007), where Dnmtl was found within the nucleus of growing oocytes isolated from preantral follicles, but not at advanced stages of differentiation within antral follicles where Dnmtl was retained in the cytoplasm (Hirasawa et al., 2008; Mertineit et al., 1998). On the contrary the de novo DNA methyltransferase protein (Dnmt3a) was found abundantly present in the nuclei of fully grown mouse oocytes (Hirasawa et al., 2008) suggesting that this form of Dnmt could be involved in the process of DNA methylation during the later aspects of oocyte differentiation. Although the presence of Dnmt3a transcript was demonstrated during early embryonic development in cow (Golding and Westhusin, 2003), the presence of both the transcript and the translated protein as well as the protein localization remain to be determined in bovine oocytes.

Immunodetection of Dnmtl protein during in vitro maturation and early embryonic development was aimed to compare the behavior of bovine Dnmtl with that described during the development of the wild-type mouse. We found that bovine Dnmtl does associate with the chromatin neither at the MII stage nor at the pronuclear stage. A similar Dnmtlo localization has been described in mouse when specific anti Dnmtlo antibody or antibodies that recognized both the isoforms were used (Carlson et al., 1992; Cirio et al., 2008; Grohmann et al., 2005; Hirasawa et al., 2008; Kurihara et al., 2008). At the 8 cells stage, the mouse Dnmtlo 
enters the nuclei, presumably to maintain the methylation patterns of imprinted loci (Howell et al., 2001; Mertineit et al., 1998). Our data indicate that an analogous process might be present in the bovine 8-16 cells stage embryo, as the Dnmtl localization suggests a nucleo-cytoplasmic trafficking. Until recently it was thought that Dnmtlo was the only form of Dnmtl protein present in mouse oocytes and preimplantation embryos (Ratnam et al., 2002). However new evidences have demonstrated the presence of the somatic form, Dnmtls, in association with chromatin in MII stage oocytes as well as in the nucleus throughout preimplantation development (Cirio et al., 2008; Hirasawa et al., 2008; Kurihara et al., 2008; reviewed in Branco et al., 2008). These findings strongly support the hypothesis that the combination of Dnmtlo and Dnmtls proteins works together to ensure the accurate inheritance of genomic imprints in the mouse (Cirio et al., 2008). However it must be pointed out that Dnmtls is present at very low concentration when compared to the oocyte specific form (Cirio et al., 2008; Hirasawa et al., 2008; Kurihara et al., 2008). For example, it has been estimated that the concentration of Dnmtls protein in mouse MII oocytes is approximately 1/2000th of the Dnmtlo protein concentration (Cirio et al., 2008). In this view, is it not surprising that the localization of Dnmtls in cow, which represents the solely form of Dnmtl in this species, reflects that of Dnmtlo during mouse development. Accordingly, it has been shown that there is no functional difference between these two isoforms (Ding and Chaillet, 2002). Furthermore, it must be considered that mouse and bovine preimplantation embryos are different with respect to the timing of genomic activation ( 2 cells stage for the mouse and 8-16 cells stage for the bovine), and to the timing of the establishment of new methylation patterns during early development, which is observed at the blastocyst stage in mouse (Dean et al., 2003; Dean et al., 2001), while it starts at the 16-cells stage onwards in bovine (Dean et al., 2003; Dean et al., 2001; Maalouf et al., 2008). Thus we cannot exclude that the functional meaning of the trafficking of Dnmtl within the nuclei of 8-16 cells stage embryos may go beyond the maintaining of the methylation pattern of imprinted genes.

In conclusion, the present work can provide useful elements for the characterization of Dnmtl function during the late stage of oocyte differentia- tion, maturation and early embryonic development in mammals. Our findings could be of mechanistic interest to better understanding the role of nuclear architecture in epigenetic maturation and genomic stability of the female germ line.

\section{Acknowledgements}

The authors would like to thank Prof. Cristiano Rumio, Dr. Silvia Gariboldi and Dr. Marco Palazzo of the "Gruppo Interdisciplinare di Microscopia" of the Department of Human Morphology, University of Milan, the "Nikon Educational Project" and Dr. Marco Cicuttin, Nikon Italia, for their excellent assistance for LSCM imaging.

The present work has been awarded with the Young Histochemist Award by the International Federation of Histochemistry and Cytochemistry "13th Congress of the International Federation of Societies for Histochemistry and Cytochemistry 2008" held in Gdansk, Poland, 23-27 August 2008, at the Medical University of Gdansk.

\section{References}

Albertini DF, Sanfins A, Combelles CM. Origins and manifestations of oocyte maturation competencies. Reprod Biomed Online 2003;6: 410-5.

Bao S, Obata Y, Carroll J, Domeki I, Kono T. Epigenetic modifications necessary for normal development are established during oocyte growth in mice. Biol Reprod 2000;62:616-21.

Beaujean N, Hartshorne G, Cavilla J, Taylor J, Gardner J, Wilmut I, et al. Non-conservation of mammalian preimplantation methylation dynamics. Curr Biol 2004;14:R266-7.

Bestor TH. The DNA methyltransferases of mammals. Hum Mol Genet 2000;9:2395-402.

Bird A. DNA methylation patterns and epigenetic memory. Genes Dev 2002;16:6-21.

Bourc'his D, Le Bourhis D, Patin D, Niveleau A, Comizzoli P, Renard $J P$, et al. Delayed and incomplete reprogramming of chromosome methylation patterns in bovine cloned embryos. Curr Biol 2001;11: 1542-6.

Branco MR, Oda M, Reik W. Safeguarding parental identity: Dnmtl maintains imprints during epigenetic reprogramming in early embryogenesis. Genes Dev 2008;22:1567-71.

Cardoso MC, Leonhardt $\mathrm{H}$. DNA methyltransferase is actively retained in the cytoplasm during early development. J Cell Biol 1999; 147:25-32.

Carlson LL, Page AW, Bestor TH. Properties and localization of DNA methyltransferase in preimplantation mouse embryos: implications for genomic imprinting. Genes Dev 1992;6:2536-41.

Cirio MC, Ratnam S, Ding F, Reinhart B, Navara C, Chaillet JR. Preimplantation expression of the somatic form of Dnmtl suggests a role in the inheritance of genomic imprints. BMC Dev Biol 2008;8:9.

De La Fuente R. Chromatin modifications in the germinal vesicle (GV) of mammalian oocytes. Dev Biol 2006;292:1-12.

Dean W, Santos F, Reik W. Epigenetic reprogramming in early mammalian development and following somatic nuclear transfer. Semin Cell Dev Biol 2003;14:93-100.

Dean W, Santos F, Stojkovic M, Zakhartchenko V, Walter J, Wolf E, et al. Conservation of methylation reprogramming in mammalian 
development: aberrant reprogramming in cloned embryos. Proc Nat Acad Sci U S A 2001;98:13734-8.

Ding $F$, Chaillet JR. In vivo stabilization of the Dnmtl (cytosine-5)methyltransferase protein. Proc Natl Acad Sci USA 2002;99: 14861-6.

Fuks F, Hurd PJ, Wolf D, Nan X, Bird AP, Kouzarides T. The methylCpG-binding protein MeCP2 links DNA methylation to histone methylation. J Biol Chem 2003;278:4035-40.

Golding MC, Westhusin ME. Analysis of DNA (cytosine 5) methyltransferase mRNA sequence and expression in bovine preimplantation embryos, fetal and adult tissues. Gene Expr Patterns 2003;3:551-8.

Grohmann M, Spada F, Schermelleh L, Alenina N, Bader M, Cardoso MC, et al. Restricted mobility of DnmtI in preimplantation embryos: implications for epigenetic reprogramming. BMC Dev Biol 2005;5:18.

Hirasawa R, Chiba H, Kaneda M, Tajima S, Li E, Jaenisch R, et al. Maternal and zygotic Dnmtl are necessary and sufficient for the maintenance of DNA methylation imprints during preimplantation development. Genes Dev 2008;22:1607-16.

Howell CY, Bestor TH, Ding F, Latham KE, Mertineit C, Trasler JM, et al. Genomic imprinting disrupted by a maternal effect mutation in the Dnmtl gene. Cell 2001;104:829-38.

Jeong YS, Oh KB, Park JS, Kim JS, Kang YK. Cytoplasmic localization of oocyte-specific variant of porcine DNA methyltransferase-1 during early development. Dev Dyn 2009.

Kafri T, Gao X, Razin A. Mechanistic aspects of genome-wide demethylation in the preimplantation mouse embryo. Proc Natl Acad Sci USA 1993;90:10558-62.

Kageyama S, Liu H, Kaneko N, Ooga M, Nagata M, Aoki F. Alterations in epigenetic modifications during oocyte growth in mice. Reproduction 2007;133:85-94.

Kang YK, Koo DB, Park JS, Choi YH, Chung AS, Lee KK, et al. Aberrant methylation of donor genome in cloned bovine embryos. Nat Genet 2001;28:173-7.

Kurihara Y, Kawamura Y, Uchijima Y, Amamo T, Kobayashi H, Asano T, et al. Maintenance of genomic methylation patterns during preimplantation development requires the somatic form of DNA methyltransferase 1. Dev Biol 2008;313:335-46.

Lepikhov K, Zakhartchenko V, Hao R, Yang F, Wrenzycki C, Niemann $\mathrm{H}$, et al. Evidence for conserved DNA and histone $\mathrm{H} 3$ methylation reprogramming in mouse, bovine and rabbit zygotes. Epigenetics Chromatin 2008;1:8.

$\mathrm{Li}$ E. Chromatin modification and epigenetic reprogramming in mammalian development. Nat Rev Genet 2002;3:662-73.

Lodde V, Modina S, Galbusera C, Franciosi F, Luciano AM. Large-scale chromatin remodeling in germinal vesicle bovine oocytes: interplay with gap junction functionality and developmental competence. Mol Reprod Dev 2007;74:740-9.

Lodde V, Modina S, Maddox-Hyttel P, Franciosi F, Lauria A, Luciano AM. Oocyte morphology and transcriptional silencing in relation to chromatin remodeling during the final phases of bovine oocyte growth. Mol Reprod Dev 2008;75:915-24.

Luciano AM, Lodde V, Beretta MS, Colleoni S, Lauria A, Modina S. Developmental capability of denuded bovine oocyte in a Co-culture system with intact cumulus-oocyte complexes: Role of cumulus cells, cyclic adenosine 3',5'-monophosphate, and glutathione. Mol Reprod Dev 2005;71:389-97.

Maalouf WE, Alberio R, Campbell KH. Differential acetylation of histone $\mathrm{H} 4$ lysine during development of in vitro fertilized, cloned and parthenogenetically activated bovine embryos. Epigenetics 2008;3:199-209.

Mayer W, Niveleau A, Walter J, Fundele R, Haaf T. Demethylation of the zygotic paternal genome. Nature 2000;403:501-2.

Mertineit C, Yoder JA, Taketo T, Laird DW, Trasler J M, Bestor TH. Sexspecific exons control DNA methyltransferase in mammalian germ cells. Development (Cambridge, England) 1998;125:889-97.

Modina S, Beretta M, Lodde V, Lauria A, Luciano AM. Cytoplasmic changes and developmental competence of bovine oocytes cryopreserved without cumulus cells. Eur J Histochem 2004;48:337-46.

Monk M, Boubelik M, Lehnert S. Temporal and regional changes in DNA methylation in the embryonic, extraembryonic and germ cell lineages during mouse embryo development. Development (Cambridge, England) 1987;99:371-82.

Oswald J, Engemann S, Lane N, Mayer W, Olek A, Fundele R, et al. Active demethylation of the paternal genome in the mouse zygote. Curr Biol 2000;10:475-8.

Ratnam S, Mertineit C, Ding F, Howell CY, Clarke HJ, Bestor TH, et al. Dynamics of Dnmtl methyltransferase expression and intracellular localization during oogenesis and preimplantation development. Dev Biol 2002;245:304-14.

Reik W, Dean W, Walter J. Epigenetic reprogramming in mammalian development. Science 2001;293:1089-93.

Reik W, Santos F, Mitsuya K, Morgan H, Dean W. Epigenetic asymmetry in the mammalian zygote and early embryo: relationship to lineage commitment? Philos Trans R Soc Lond B Biol Sci 2003;358:1403-9; discussion 1409.

Rougier N, Bourc'his D, Gomes DM, Niveleau A, Plachot M, Paldi A, et al. Chromosome methylation patterns during mammalian preimplantation development. Genes Dev 1998;12:2108-13.

Russell DF, Betts DH. Alternative splicing and expression analysis of bovine DNA methyltransferase 1. Dev Dyn 2008;237:1051-9.

Russo V, Martelli A, Berardinelli P, Di Giacinto 0, Bernabo N, Fantasia $D$, et al. Modifications in chromatin morphology and organization during sheep oogenesis. Micros Research Tech 2007;70:733-44.

Santos F, Hendrich B, Reik W, Dean W. Dynamic reprogramming of DNA methylation in the early mouse embryo. Dev Biol 2002;241:172-82.

Spinaci M, Seren E, Mattioli M. Maternal chromatin remodeling during maturation and after fertilization in mouse oocytes. Mol Reprod Dev 2004;69:215-21.

Taylor J, Moore H, Beaujean N, Gardner J, Wilmut I, Meehan R, et al. Cloning and expression of sheep DNA methyltransferase 1 and its development-specific isoform. Mol Reprod Dev 2009;76:501-13.

Tervit HR, Whittingham DG, Rowson LEA. Successful culture in vitro of sheep and cattle ova. J Reprod Fert 1972;30:493-97.

Vassena R, Dee Schramm R, Latham KE. Species-dependent expression patterns of DNA methyltransferase genes in mammalian oocytes and preimplantation embryos. Mol Reprod Dev 2005;72: 430-6. 
V. Lodde et al. 